\title{
Ee己crearáo \\ Pensando a História da Educação com Raymond Williams
}

\author{
Marcus Aurelio Taborda de Oliveira' \\ 'Universidade Federal de Minas Gerais (UFMG), Belo Horizonte/MG - Brasil
}

RESUMO - Pensando a História da Educação com Raymond Williams'. O trabalho procura evidenciar a contribuição original do pensamento de Raymond Williams para a pesquisa em história da educação. Percorre um conjunto de conceitos-chave na obra do autor galês, sugerindo sua potência para a análise e a crítica das formas de organização da sociedade e da cultura no Brasil, com destaque para diferentes formas de educação. Conclui dimensionando a atualidade do seu pensamento não só para os intelectuais ligados ao campo educacional, ou para os historiadores da educação, mas para o próprio revigoramento do pensamento da esquerda no Brasil e no mundo.

Palavras-chave: História Social da Educação. História Social. Crítica Cultural. Raymond Williams.

ABSTRACT - Thinking the History of Education with Raymond Williams. This article seeks to emphasize the original contribution of Raymond Williams' thought to the research in history of education. It goes through an amount of key concepts in the work of the Welsh author, suggesting its potential to critique and analyze forms of society and culture organization in Brazil, with highlight to different forms of education. It concludes dimensioning the actuality of his thought not only to intellectuals linked to the educational field or to historians of education, but to the reinvigoration of the left thought in Brazil and in the world.

Keywords: Social History of Education. Social History. Cultural Critique. Raymond Williams.

Educação \& Realidade, Porto Alegre, v. 39, n. 1, p. 257-276, jan./mar. 2014. 
[...] ninguém está em condições de elevar o padrão cultural dos outros (Williams, 1978, p. 327).

Raymond Williams não é um historiador no sentido profissionalespecializado do termo, embora as suas ligações com os chamados historiadores do Partido Comunista Britânico, assim como com a tradição da história social inglesa, estejam longe de deixar qualquer dúvida. Também por essa fecunda articulação, mas, sobretudo, pela qualidade da sua produção intelectual e a sua relevância para o campo das humanidades, da educação em particular, entende-se que conhecer e explorar a sua obra para pensar a educação e a sua história é uma necessidade premente e uma oportunidade de ampliar nossas possibilidades analíticas de compreender a história dos fenômenos educativos, especialmente quando sabemos que seu pensamento impactou fortemente a Sociologia da Educação e os Estudos Curriculares.

Williams nasceu no País de Gales em 1921 e faleceu em 1988. Era neto de agricultores e filho de ferroviário. Cresceu em um ambiente de forte tradição trabalhista, de grande presença na cena britânica, com influência comunista. Ainda muito jovem, foi contemplado com uma bolsa de estudos para estudar em Cambridge, considerado por muitos como o centro da elite intelectual inglesa. Filiou-se ao Partido Comunista Britânico e lutou na Segunda Guerra Mundial. Um dos seus traços mais característicos foi ter adotado uma postura intelectual francamente militante, tendo se engajado em vários dos problemas da chamada gente comum, sobre a qual discorria em diversas oportunidades. Um exemplo da sua verve pública e militante nos foi dado pelo seu intenso debate sobre - e contra - a Guerra das Malvinas, em 1982, evento que comemorou seus 30 anos, e contra toda a política de Margareth Thatcher, a chamada Dama de Ferro, recentemente falecida e que ganhou as telas dos cinemas.

Sua intervenção política e cultural se deu através de estudos de sociologia e crítica cultural, pela produção literária, pela intervenção na mídia e por uma análise profundamente estética da cultura e da vida em sociedade. Incursionou tanto pela chamada literatura canônica (romance, poesia, teatro) quanto pelo rádio e pela televisão, uma vez que para ele não havia distinção entre cultura popular e cultura erudita ou de elite. Aliás, não tendo abandonado nunca uma análise da cultura a partir da clivagem das classes sociais, nem por isso deixou de combater formas de reducionismos que definiam a cultura a partir da última instância econômica. Quando morreu, em 1988, escrevia seu romance em três volumes intitulado O Povo das Montanhas Negras, recuperando a tradição rebelde da população da região onde nasceu, na cidade de Pandy. Infelizmente, daquele projeto só temos o primeiro dos volumes, publicado no Brasil em 1991. Em língua inglesa, foi publicado o segundo volume e o que pode ser considerado o esboço do que seria o terceiro. Naquele projeto, pôde exercitar parte das suas reflexões sobre a produção da cultura, as relações entre cultura e natureza e a tradição seletiva, noção que o tornaria amplamente conhecido no mundo acadêmico.

258 Educação \& Realidade, Porto Alegre, v. 39, n. 1, p. 257-276, jan./mar. 2014 Disponível em: <http://www.ufrgs.br/edu_realidade> 
Membro do Partido Comunista Britânico, ao lado de eminentes intelectuais, ao romper com o stalinismo ajudou a fundar a chamada new left inglesa, juntamente com Edward P. Thompson, Eric Hobsbawm, Raphael Samuel, Christopher Hill, Perry Anderson, entre outros. No âmbito do seu trabalho político e cultural, atuou, ainda, como professor de jovens e adultos trabalhadores. Seu legado, visível em suas múltiplas facetas, pode ser também observado em uma disciplina que ajudou a fundar, o que hoje conhecemos como Estudos Culturais, juntamente com Richard Hoggart e Stuart Hall, a partir da criação do Centre for Literature and Contemporary Cultural Studies, da Universidade de Birmingham, em 1964, o qual foi fechado em 2002.

Sua vasta e complexa obra expõe o programa do que seria conhecido como materialismo cultural - e não culturalista, como insistem alguns. Defendeu insistentemente a ideia de um socialismo democrático, portanto, de uma cultura comum, não autoritária e aberta à experiência, em franca oposição às formas cada vez mais refinadas e sutis de dominação desenvolvidas pelo capitalismo tardio, mas sem perder de vista o que chamaria de mente criativa já nos anos 1950, característica distintiva dos homens em relação àquilo que os cerca. Juntamente com seus companheiros militantes da nova esquerda inglesa, fundou a New Left Review, uma das mais destacadas revistas históricas do século XX, que se tornaria o centro de um debate político que levaria à ruptura no interior da nova esquerda, em função das diferentes reações aos eventos que se sucederam à invasão da Hungria pela URSS em 1956 e pela publicação do Relatório Kruschev², bem como pela forma como alguns intelectuais dessa tradição interpretaram a possibilidade de revolução na Inglaterra.

Raymond Williams foi definido por Edward Thompson, de quem era amigo mas com quem teve um áspero debate em torno do seu $O$ Campo e a Cidade, como "o melhor entre nós”, referindo-se o historiador à geração da nova esquerda, que se propunha a revigorar a tradicional cultura inglesa pela via de uma "república das letras", mas social e politicamente engajada.

$\mathrm{O}$ autor publicou mais de 30 livros, poucos deles traduzidos no Brasil ou mesmo para o português. Foram publicados no Brasil: Marxismo e Literatura (1979), Cultura e Sociedade (1978 [2011]), O Campo e a Cidade (1989), O Povo das Montanhas Negras (1991), Cultura (1991), Tragédia Moderna (2005), Palavras-Chave (2007), A Política do Modernismo: contra os novos conformistas (2010), Cultura e Materialismo (2011), além de alguns artigos e entrevistas. O seu vasto e ambicioso projeto intelectual foi anunciado em duas obras seminais e complementares: Culture and Society, de 1958, e The Long Revolution, de 1961 (ainda sem tradução brasileira), por sua vez complementados por Keywords (1977).

Educação \& Realidade, Porto Alegre, v. 39, n. 1, p. 257-276, jan./mar. 2014. Disponível em: <http://www.ufrgs.br/edu_realidade> 


\section{Williams, sua Obra e a História da Educação}

A despeito de sua visceral participação em programas de educação de adultos trabalhadores, ou até mesmo por conta disso, a obra de Raymond Williams nos oferece um conjunto de possibilidades muito profícuo para pensarmos a educação e sua história. Seu pensamento impactou as reflexões tanto na chamada Nova Sociologia Crítica da Educação, como também a História da Educação, sobretudo na Sociologia e na História do Currículo. No primeiro caso, podemos observar uma forma de apropriação da sua produção no livro de Jean Claude Forquin, Escola e Cultura (1993), no qual aparece com grande evidência a força das reflexões de Raymond Williams sobre a cultura em uma perspectiva crítica, de modo que Forquin considera sua teoria como uma das âncoras do debate educacional levado a cabo no mundo anglosaxão a partir dos anos 1960, em contraposição a outras perspectivas de corte funcionalista. Não é demais lembrar que muito do que se chamou de teorias críticas da educação se deve às formulações do intelectual galês. No caso da História do Currículo, Ivor Goodson (1995) já defendeu o currículo como uma "tradição inventada", parte de um processo ativo de seleção que nos remete à noção de tradição seletiva, de Williams. Destaque-se, ainda, a contribuição da obra de Michael W. Apple (1989, 2006), provavelmente a principal responsável pela chegada do pensamento de Williams no campo educacional, no Brasil. Nela, tanto a noção de longa revolução quanto a de cultura comum são basilares para a compreensão das relações entre currículo, poder e organização da cultura, sendo de grande relevância para os historiadores do currículo e, por conseguinte, da educação. Voltaremos a essas noções.

Em ambos os casos, boa parte do que se faz ou pensa hoje, historicamente em termos críticos, no âmbito das disciplinas escolares, do currículo e das culturas escolares, e mesmo no que se refere às formas alternativas de educação social, é devedora em alguma medida da crítica radical de Williams às formas culturais dominantes no mundo ocidental, que pareciam implodir entre meados da década de 1950 e os anos finais da década de 1960. Dominantes, sim; nunca naturais, e sempre historicamente produzidas. Ao atacar, em livro de tradução recente para o Brasil, o que chama de "novos conformistas", Williams (2010) não deixa margem de dúvidas quanto à sua preocupação com a voga pós-moderna, que em nome da invenção do sempre novo olvida as condições de possibilidade histórica da produção cultural, portanto, educacional, e o fundo profundamente social e coparticipativo daquela produção. Para ele, no plano cultural o pós-modernismo seria ainda uma experiência moderna.

Ao tratar desta maneira a experiência da modernidade, o autor nega de saída a ênfase em todas as formas subjetivistas de pensar as relações entre ação individual, a sociedade e a cultura, bem como reafirma o caráter eminentemente histórico de todas as formas de produção ou apagamento cultural. Dessa ênfase nasce a sua crítica a uma

260 Educação \& Realidade, Porto Alegre, v. 39, n. 1, p. 257-276, jan./mar. 2014 Disponível em: <http://www.ufrgs.br/edu_realidade> 
perspectiva pós-moderna que perdeu de vista a sociedade e se enredou em uma perspectiva consumista/individualista. Exemplo de sua crítica recai sobre a chamada pop art. Segundo Williams, essa perspectiva pósmodernista proclamaria um tipo de experiência quase niilista e contribuiria muito pouco para a renovação da sociologia da cultura. Não é pouco seu diagnóstico, feito ao longo da década de 1970, considerando que hoje vivemos em um tempo que insistentemente proclama a primazia do indivíduo, o qual parece destinado a viver em um mundo eternamente presentificado, no qual a história não seria mais do que arte de antiquário ${ }^{3}$. De todo modo, ao tratar o pós-modernismo como um desenvolvimento do próprio modernismo, Williams acentua a dialética com a qual inquire a cultura. Foge de esquemas binários para reconhecer, por exemplo, que a televisão e o cinema seriam as formas estéticas por excelência de uma modernidade que incluiu as massas.

Mas acompanhemos parte do processo de produção das suas principais preocupações: a história social da linguagem, as noções de cultura e tradição seletiva, com sua ênfase na cultura comum, e as suas considerações sobre as relações entre cultura e natureza, todas de grande relevância para a pesquisa em História da Educação.

Em 2007, é lançado no Brasil Palavras-Chave (Keywords), publicado pela primeira vez na Inglaterra, em 1977. Segundo explanação do próprio Williams, essa obra foi gestada desde o período de produção de Cultura e Sociedade (1958) e The Long Revolution (1961). Nessas duas obras anteriores, o autor se lança ao entendimento da produção cultural em termos de relações conflituosas; estas, apagadas pela crítica conservadora, obscurecem o sentido histórico da mudança cultural, mantendo uma tendência antidemocrática de produção e acesso à cultura, fundada na ideia de consenso entre grupos antagônicos. Desse processo ganharia força a ideia de que haveria uma cultura de elite, refinada, e uma cultura popular, desqualificada em relação à primeira, como é latente no debate educacional brasileiro desde as primeiras décadas do século XX.

Williams explica que no seu processo de produção intelectual se deparou com cinco expressões (conceitos) considerados por ele fundamentais para a análise e a crítica cultural, em aproximadamente 200 anos que cobrem a afirmação da chamada modernidade: indústria, democracia, classe, arte e cultura. Essas noções se desdobraram em 131 outros termos centrais para compreender a mudança cultural no âmbito de uma sociedade ${ }^{4}$. Naquela obra, que não pretende ser um dicionário, um glossário, mas esmiuçar um vocabulário próprio do desenvolvimento cultural de uma sociedade específica - a inglesa - nos últimos 200 anos, Williams demonstra a sua preocupação com a história social da linguagem, da qual nasce Palavras-chave, decorrente de um combate intelectual contra os defensores do linguist turn, que parecem ter reduzido tudo à primazia da linguagem, esquecendo os múltiplos vetores que orientam e definem a produção cultural (inclusive a linguagem) ${ }^{5}$.

Educação \& Realidade, Porto Alegre, v. 39, n. 1, p. 257-276, jan./mar. 2014.

Disponível em: <http://www.ufrgs.br/edu_realidade> 
Pensando a História da Educação com Raymond Williams

No entanto, mais do que fazer a defesa sumária de uma tradição de pensamento contra outras, o seu rigor se volta também para a crítica interna da própria tradição marxista, quando definirá, em outra obra recentemente lançada no Brasil, que a ideia de determinação, tão cara ao pensamento de esquerda, é "de grande complexidade linguística e teórica. A linguagem da determinação e, ainda mais, do determinismo, foi herdada de explicações idealistas e especialmente teológicas do mundo e do homem" (Williams, 2011, p. 43-44). Assim, o autor mergulha na busca da compreensão histórica do surgimento e da mudança de conceitos-chave que ajudarão a compreender como a cultura, mais do que um subproduto da economia, é o solo fértil da própria produção da vida em sociedade, tanto na sua dimensão material, como na sua dimensão sensível, sem que isso implique qualquer concessão ao subjetivismo. Dessa busca nasce um diálogo crítico muito fecundo com outras tradições da crítica cultural, além da marxista, seja aquela do funcionalismo, seja do pós-estruturalismo ou do genericamente caracterizado pós-modernismo, diante das quais o autor constantemente irá reiterar as premissas de um materialismo cultural. Fiel à tradição do materialismo dialético, o autor faz a sua crítica da crítica cultural mirando interlocutores afeitos àquela tradição, mas também aqueles seus detratores, mostrando, como já indicado, que o pós-modernismo é, em algumas das suas expressões, a continuidade do modernismo (2011, p. LV) ${ }^{6}$.

Por si só, o resultado de Palavras-Chavejá seria estimulante para o campo educacional, uma vez que permite entender o percurso de construção e de mudança de sentido de um amplo léxico que afetou em cheio as formas de educação na modernidade, pelo menos no âmbito de influência da língua inglesa. Mas, além disso, a lembrança que os conceitos comportam uma história e que esta se faz em determinadas ambiências parece dizer muito àqueles que se preocupam com a história da educação, seja no plano da investigação sobre intelectuais e ideias, seja sobre prescrições curriculares, enfim, sobre todas as formas de pensar e dizer sobre a educação ao longo da história, às quais às vezes damos pouca importância ou as descarnamos da sua base sócio-histórica.

Certamente, quando buscamos compreender intelectuais, ideias, culturas escolares, tradição, mudança, formação, sentimentos, discursos, entre tantas outras coisas no âmbito educacional, a produção de Raymond Williams nos oferece um rico repertório de possibilidades analíticas que começam na sua obsessão pela construção histórica dos conceitos e na minúcia da sua busca pela mudança dos seus sentidos ao longo do tempo. Por exemplo, tornou-se comum falar em modernidade no campo da história da educação, mas nem sempre há a preocupação em deixar claro o que é a modernidade sobre a qual se escreve, se os processos que analisamos se inscrevem de alguma maneira em um fluxo temporal moderno ou se a modernidade brasileira é um simples reflexo de vogas estrangeiras, e se poderia ser assim chamada. Ou seja, como soe acontecer com diferentes expressões que são conceitos, ainda que 
descritivos, às vezes nos deparamos com a apropriação completamente acrítica de um determinado léxico e fazemos dele um uso arbitrário. Ao historiador da educação - e não só a ele - a produção de palavras, conceitos e sentidos, bem como a sua mudança ao longo do tempo e a sua variabilidade conforme o contexto são fundamentos historiográficos importantes para a compreensão de qualquer processo histórico que envolva a análise das transformações no âmbito da cultura ${ }^{7}$. Nessa sua empreitada, Raymond Williams buscou superar dicotomias tais como base/superestrutura, popular/erudito, ciência/arte, razão/emoção, cultura/política, subalterno/dominante etc., bipolarizações que enfraquecem o potencial explicativo da linguagem para a compreensão dos fenômenos históricos, sobretudo, os educacionais.

\section{Ambiência como Estrutura de Sentimentos Definida por uma Cultura Comum}

A partir da sua caracterização, parece pertinente explorar algumas das possíveis contribuições de Raymond Williams para as pesquisas no âmbito da história da educação, tendo como referência a história dos intelectuais, do currículo, da educação social e das sensibilidades. Não é o objetivo deste escrito averiguar ou inventariar o usos da obra do crítico na historiografia da educação brasileira, mas pensar sobre sua fecundidade para o campo.

Para este autor, a cultura pode ser entendida como a síntese da economia, da política e da sociedade, e se desenvolve a partir de uma longa revolução, conforme expressa em sua obra de 1961, a qual teria sua culminância em três dimensões: a política, expressa na consolidação da democracia, a econômica, manifesta na supremacia do capitalismo industrial, e a cultural, que garantiu a expansão das oportunidades culturais e educacionais na metade do século XX à quase totalidade da população inglesa. Com tal caracterização, Williams (2003), sempre lembrando que as suas análises recaem sobre a órbita da língua inglesa, ainda que faça alusões a outras tradições, ajudou a desenvolver noções teóricas importantes, como cultura, cultura comum, estrutura de sentimentos e tradição seletiva, as quais têm grande potência para pensarmos a produção historiográfica na área da educação. Seu impacto no pensamento crítico argentino, por exemplo, é aquilatado pelo ensaio de Beatriz Sarlo (2005, p. 86): "Penso que o que me atraiu nele foi a possibilidade de sair do círculo virtuoso da ideologia francesa”. Lembremos que pontificava no pensamento argentino de então, imerso em uma sangrenta ditadura, o formalismo do estruturalismo de Louis Althusser e outros intelectuais que não compreendiam a imbricação entre cultura e política.

Para Williams, a cultura pode ser caracterizada em pelo menos três dimensões:

Educação \& Realidade, Porto Alegre, v. 39, n. 1, p. 257-276, jan./mar. 2014. 
1) a ideal, em que a cultura é um estado ou processo de perfeição em termos de certos valores absolutos e remete a uma condição humana universal;

2) a documental, segundo a qual cultura é o conjunto das obras intelectuais e imaginativas que registram a experiência humana;

3) a social, sendo esta a descrição de um modo determinado de vida, o qual expressa certos valores e significados não somente através da arte e da aprendizagem, mas também em instituições e no comportamento ordinário.

O autor defende que uma definição apropriada e abrangente deve incluir as referências dos três tipos mencionados, ou seja, que seria inadequada qualquer definição que excluísse a referência às outras (Williams, 2003; 2007). Faz, ainda, uma distinção entre três níveis de cultura:

1) a cultura vivida em um tempo e lugar determinados;

2) a cultura registrada em todos os níveis - a cultura produzida em um dado período;

3) a cultura da tradição seletiva.

A cultura vivida de um momento e um lugar determinados só é plenamente acessível para quem neles vive. Já a cultura registrada (dos atos ordinários mas também da arte, da educação etc.) se define e é definida por um tempo e lugar específico e compõe boa parte do que é o suporte documental dos historiadores. Por fim, a cultura da tradição seletiva, uma vez que o que sobrevive não é determinado por seu próprio tempo, mas pelos tempos posteriores, que gradativamente compõem uma tradição: "Teoricamente, um período se documenta; na prática, esse documento é absorvido em uma tradição seletiva, e ambos são diferentes da cultura vivida" (Williams, 2003, p. 59).

Observe-se que a primeira das asserções identificadas por Williams nos aproxima bastante do entendimento de civilização, e pode ajudar a entender muitas das retóricas presentes nos discursos educacionais sobre a civilização dos costumes, preconizada no Brasil desde o século XIX, pelo menos. Ou seja, haveria que se pensar uma dimensão universal do que seria a produção e a mudança cultural, que pode ser expressa, não sem problemas identificados pelo autor, na noção de totalidade. Mas a sua caracterização da totalidade guarda uma nuança incomum, sobretudo em relação à ortodoxia marxista. Para ele, “[...] a questão-chave sobre qualquer noção de totalidade na teoria da cultura é se essa noção inclui a de intenção" (Williams, 2011, p. 50). E segue:

A intenção, a noção de intenção, recupera a questão-chave, ou melhor, a ênfase central. Pois embora seja verdade que qualquer sociedade é um todo complexo de tais práticas, também é verdade que toda sociedade tem uma organização e uma estrutura específicas, e que os princípios dessa organização e dessa estrutura podem ser vistos como diretamente relacionados a certas intenções 
sociais, pelas quais definimos a sociedade, intenções que, em toda a nossa experiência, têm sido regidas por uma classe particular (Williams, 2011, p. 50).

Se o autor não abandona uma das principais premissas oriundas da tradição marxista, não se deixa iludir pelo simplismo da noção base-superestrutura, comumente usada, inclusive em estudos do campo educacional. Seguindo a senda aberta por Antonio Gramsci, Williams defenderá que a noção de totalidade só é útil para o entendimento da mudança cultural se for tratada diretamente relacionada à noção de hegemonia, uma vez que, para o pensador sardo, "[...] a hegemonia supõe a existência de algo verdadeiramente total" (Williams, 2011, p. 51). Remata, então: "E, ao contrário das noções gerais de totalidade, a hegemonia possui a vantagem de enfatizar, ao mesmo tempo, a realidade da dominação" (p. 52). Nada mais próprio da pena de Williams. Entre o enrijecimento provocado pela ortodoxia e o esvaziamento dos sentidos das múltiplas formas de dominação que constantemente se atualizam, o autor se equilibra na tensão entre ação e pensamento, ser e consciência sociais, experiência e determinação cultural.

A partir dessa constatação, é possível pensar a ideia de cultura comum, explorada por Williams a partir da tradição do romantismo inglês. Essa noção se opunha, segundo o autor, na fase de argumentação que se desenvolveu entre os anos 1850 e 1860, à noção corrente de cultura como alta cultura, ou cultura dominante. Ao longo do tempo, no entanto, essa concepção teve de ser aprimorada, ou desdobrada, para dar conta das divisões e relações de conflito existentes dentro da cultura. Basicamente, a cultura comum se caracterizaria por um conjunto de realizações baseadas na interação da comunidade (contrapondo-se ao individualismo competitivo). Tem o sentido de cultura compartilhada, que inclui a diversidade, mas também a experiência individual, que é sempre estruturada socialmente. Para o autor, arte e cultura - acrescentaria a educação - são coisas ordinárias, como todas as formas de produção que emanam da "mente criativa", uma característica exclusivamente humana (2003, p. 90-93). Ou seja, elas se inscrevem na esfera da vida comum, sendo toda a forma de classificação na vida, na cultura ou na arte, uma forma de afirmação hegemônica.

Nesse caso, não se trata de captar uma suposta totalidade abstrata, mas de entender como determinadas formas de organização da cultura foram e são desenvolvidas a partir de relações de poder que afirmam alguns atores, produtos e consumidores de cultura - a alta cultu$r a$, por exemplo - em relação à maioria. Certamente isso ajudará a definir um conjunto de ênfases e omissões na cultura, os quais definirão comportamentos, atitudes, práticas que, por sua vez, gestarão sentidos e sensibilidades que serão também distintas conforme cada grupo social, de um lado, e toda aquela sociedade, de outro, caracterizando uma verdadeira educação das sensibilidades, seja pela via da educação formal, seja pelos processos de formação observados em outros espaços de educação e usufruto do tempo livre.

Educação \& Realidade, Porto Alegre, v. 39, n. 1, p. 257-276, jan./mar. 2014.

Disponível em: <http://www.ufrgs.br/edu_realidade> 
Seja nos trejeitos daqueles que cultuam o vinho em uma adega especializada, seja na rusticidade de um balcão de bar frequentado por trabalhadores que bebem etanol na volta à casa depois de um dia de trabalho, se estabelece um claro divisor do que poderia ser definido como cultivado, culto ou elaborado, e aquilo que é comumente caracterizado como rústico, popular ou simples, que afetará não só os lazeres e as formas consideradas educadas de uma determinada sociedade, mas até mesmo como serão definidas as oportunidades de acesso a uma vida de mais ou menos penúria para os de baixo ou os dominantes. Assim, é possível afirmar que uma unidade como nação, por exemplo, comporta uma multiplicidade de possibilidades ou tipos de cultura comum, seja pelas línguas que fala, seja pelos símbolos que mobiliza para afirmar-se e pelo maior ou menor grau de reconhecimento e pertencimento que seus integrantes sentem em relação aos outros. Em um país de ampla diversidade étnica e cultural, o alerta de Williams parece um ensinamento poderoso.

Esse pressuposto permite entender, no âmbito dos interesses dos educadores - e dos historiadores da educação, em particular - a eficácia hegemônica de noções tais como nacionalismo, ontem, e individualismo, hoje; a histórica apologia do trabalho como redenção, para alguns grupos sociais que não trabalham como outros; a retórica da morigeração dos costumes dos pobres independente da sua corrupção pelos ricos, a apologia da competição em uma sociedade de oportunidades desiguais. Mas também discursos contemporâneos que advogam a volta à natureza, caros aos debates sobre lazer desde o início do século XX, pelo menos (Corbin, 2001), como se a natureza não fosse uma invenção do próprio homem que, na tentativa de dominá-la e apaziguá-la, se apartou da vida das coisas, além das retóricas que denunciam o fracasso da escola, como se a escolarização fosse um dado e não um processo de civilização marcadamente centrado na autoridade, para o qual, aliás, a sociedade brasileira tem dado pouca atenção $0^{8}$.

Na pena de Williams, se não é possível perder de vista a experiência, não é demais lembrar que ela se estrutura em termos basicamente societários, em relações que muitas vezes escapam à premissa de autonomia ou autodeterminação dos indivíduos, pela própria força dos modos de seleção e transmissão da cultura. Nessa perspectiva se entrelaçam a dimensão estrutural com a contextual, a individual com a societária, a documentação sobre a vida com a própria vida vivida. Por isso, se para ele a determinação e a totalidade marcam, em grande medida, as formas de organização da cultura, nem por isso elas podem ser definidas fora dos embates reais que constituem cada sociedade. Sua análise da luta de classes não está, pois, em um mundo ideal e abstrato forjado na mente do intelectual, mas no dia a dia da dominação que se renova e das forças que com ela diuturnamente também se debatem.

É justamente nesse equilíbrio dinâmico de forças antagônicas que se afirma o sentido de cultura comum, como cultura compartilha- 
da, baseada no mutualismo e na reciprocidade, mas também na ideia de que um tempo, um espaço e aquilo que ali se produz e se pode fruir dizem respeito a todos os indivíduos e grupos naquela cultura inseridos. Daí a sua denúncia da falácia de representações como cultura popular e cultura de elite, ou alta e baixa cultura, por exemplo. Para ele, formulações como essas estão carregadas de um sentido ideológico que deve ser desvendado em cada contexto pelo historiador. Quantas vezes nos deparamos, em nossas fontes, com retóricas que reivindicavam a educação do povo, como se os grupos dominantes também não devessem ser mais e melhor educados, como se o povo fossem os outros? Quantas vezes nos preocupamos com esse tipo de representação que advoga a necessidade de controlar tempos, espaços e atividades dos pobres, independentemente do que fazem os mais ricos com eles? E quantas vezes ainda se faz apologia da cultura popular como expressão de formas de resistência, sem que se leve em consideração que, por vezes, o popular nada mais é do que o resto deixado pelos jogos de poder? Por outro lado, que esforços fazemos para entender ênfases e omissões como parte do processo histórico, e não apenas como atributo de uma mente conspiratória? Preocupações como estas têm orientado um conjunto de estudos sobre o pensamento social brasileiro, mais especificamente, a trajetória de intelectuais considerados periféricos, como José Francisco da Rocha Pombo (Taborda de Oliveira, 2013), bem como as formas como as pessoas comuns operavam com os códigos culturais de maneira a dimensionar a fruição da sua própria vida (Oscar; Taborda de Oliveira, 2013).

A dimensão contextual das formulações de Williams leva o crítico galês a sugerir a noção de estrutura de sentimentos para pensar o lugar do pensamento - logo, tanto do intelectual como de homens e mulheres comuns - na cultura. Se existe uma mente criativa ela estaria balizada por essa estrutura de sentimentos, que muito tem a ver com ambiência, rede de sociabilidade e outros conceitos de franca aceitação, hoje, para a compreensão da história dos intelectuais, dos discursos e das prescrições. Novamente, a noção de uma mente genial ou brilhante, de autores portadores de grandes ideias, para Williams só faz sentido se entendidas as condições de produção e atuação de autores e ideias em cada sociedade determinada. $\mathrm{O}$ autor não deixa de alertar para as dificuldades de análise de outros lugares e tempos, o que é importante em um exercício como este aqui desenvolvido. Inclusive por esse motivo foi criticado por alguns dos seus interlocutores, como Perry Anderson, uma vez que suas análises seriam excessivamente restritas ao universo britânico (Pinkney, 2011), aspecto que tratou de enfrentar tardiamente.

Ainda assim, o autor afirma a necessidade de se perceber a estrutura de sentimento que caracteriza o modo de vida de uma determinada geração (já que as concepções de caráter social ou padrão de cultura lhe pareciam muito abstratas). Essa estrutura não é formalmente aprendida, e cada geração terá sua própria estrutura, que - aparentemente - não procede de parte alguma: a nova geração responde a seu modo ao mun-

Educação \& Realidade, Porto Alegre, v. 39, n. 1, p. 257-276, jan./mar. 2014.

Disponível em: <http://www.ufrgs.br/edu_realidade> 
Pensando a História da Educação com Raymond Williams

do que herdou, adota continuidades, reproduz muitos aspectos da organização, mas "[...] de certo modo, sente toda a sua vida de forma diferente e molda sua resposta criativa em uma nova estrutura de sentimento" (2003, p. 58). Assim, a estrutura de sentimentos definiria a cultura de um período e lugar e seria responsável por permitir, por exemplo, que nós historiadores nos ocupemos dos temas dos quais nos ocupamos, na forma como o fazemos, seja no âmbito da nossa intervenção sociopolítica cotidiana, seja no âmbito da nossa produção como intelectuais. Essa estrutura de sentimento permitiria a elocução, a enunciação, dentro de um universo compartilhado de expectativas e necessidades. Assim, elide-se totalmente a ideia de que alguém possa estar além ou aquém do seu tempo, por exemplo. Sejam mais avançadas ou atrasadas, as ideias formam parte de uma mesma estrutura de sentimento, definida pela imersão dos indivíduos e dos grupos sociais em tempos e espaços específicos, com problemas culturais compartilhados, e em fluxos de inter-relação com outros grupos, espaços e tempos também produtores de cultura e com interesses comuns. A sua mola propulsora é a cultura comum, já definida, e ela é tão dinâmica e ativa quanto pode ser cada sociedade particular e as formas de educação social que ela produz e mobiliza.

A estrutura de sentimentos de uma época e lugar remete à noção de tradição seletiva, que seria um processo seletivo bastante drástico daquilo que foi, em uma determinada ambiência social, definido como algo digno de ser perpetuado. Por motivos diversos, que incluem relações de poder político, disponibilidade econômica e visibilidade cultural, mas também a clivagem ideológica, determinadas orientações intelectuais se fixam na cultura e definem o limite da circulação de ideias opostas ou contrárias, no seu tempo. Para Williams,

\section{Até certo ponto, a seleção começa dentro do período de produção, mesmo: de toda a massa de atividades são se- lecionadas certas coisas, elas são valorizadas e definidas como essenciais. Em geral, essa seleção refletirá a orga- nização do período no seu conjunto, ainda que isso não signifique que depois sejam confirmados aqueles valores e aquelas ênfases (2003, p. 59).}

Não estranha que tal noção tenha impactado tão fortemente os estudos críticos no campo da educação. Assim, ao olharmos para a cultura nos deparamos com um universo de questões que ganharam claridade quando pensamos a partir dessa noção desenvolvida por Raymond Williams. Afinal, por que desenvolvemos certas formas de usufruto do tempo livre e não outras, com as mesmas condições materiais que dispomos? Por que isso é tão distinto entre diferentes grupos sociais, ao mesmo tempo em que o consumo de alguns parece unificá-los? Que mecanismos permitem o lazer e a escolarização, por exemplo, se configurarem, ao longo do tempo, como espaços de reforço hegemônico, onde produção material e consumo cultural com frequência estão alheios a quaisquer perspectivas de valorização dos indivíduos e do

268 Educação \& Realidade, Porto Alegre, v. 39, n. 1, p. 257-276, jan./mar. 2014 Disponível em: <http://www.ufrgs.br/edu_realidade> 
próprio grupo social? Como se desenvolveu um sistema educacional em que o Estado paga diretamente para a maioria ter acesso a uma instituição pública precária como a escola brasileira, enquanto fomenta com recursos públicos a possibilidade de os mais ricos terem acesso a instituições que se converteram em verdadeiros shoppings culturais? Como compreender historicamente o financiamento da educação pública brasileira e seus limites, sem entender que essa mesma educação não se converteu em um problema de ponta da própria sociedade brasileira? Como compreender os discursos sobre a necessidade de lazer dos mais pobres quando as formas de trabalho a que estão submetidos não lhes permite nem mesmo ter tempo livre, quanto menos usufruir dele?

Essas inquietações, que podem ser desenvolvidas em amplos problemas de pesquisa, só podem ser adequadamente enfrentadas se entendermos que as sociedades se fazem e refazem em cada novo momento de conflito ou de consenso. Mais do que a maquinação de um Estado demiurgo todo-poderoso, precisamos indagar como, no Brasil, a própria sociedade se erigiu sobre princípios tais que permitem conceber a maior parte da população alijada do acesso à cultura, ao lazer, à educação etc., além dos meios elementares de subsistência. Mas, com Williams, podemos aprender também a enfrentar aquele traço tão perverso erigido por muitos intérpretes do Brasil, o qual depositou na natureza a responsabilidade pelas nossas mazelas mais perversas. No caso da cultura e da sociedade, as mazelas nunca são naturais.

Portanto essa noção não é estática. Atende a uma dialética entre a dinâmica do que é geracional e a estabilidade/mudança social e cultural em cada momento. Daí, para o crítico, a importância de instituições acadêmicas e educativas, capazes de recuperar e preservar aquilo que poderia ser esquecido, atuando como verdadeiros lugares de memória, bem como o valor da imprensa como fomentadora do debate público plural na modernidade. Obviamente, a sua análise não desconsidera que todas essas instituições são cortadas por disputas de poder definidas pela luta hegemônica em cada sociedade. Talvez a crise das ideologias que antecipou a crise que levaria à queda do Muro de Berlim tenha permitido o relativo apagamento das preocupações de Williams com a cultura em uma sociedade de classes. Aquelas preocupações, acentuadas nos primeiros tempos do Centre for Contemporary Cultural Studies, da Universidade de Birmingham, perdem força em relação à ênfase posta nas questões afeitas à geração, ao gênero ou ao indivíduo, conforme podemos observar no desenvolvimento dos Estudos Culturais nos últimos 20 anos.

\section{Desnaturalizando a Cultura}

Contra a ideia não incomum de que o homem é também nature$z a$, Raymond Williams produziu, em franco debate com a psicologia, mas também com outras disciplinas fortemente ancoradas em premissas evolucionárias, um conjunto de ensaios nos quais enfrenta o debate

Educação \& Realidade, Porto Alegre, v. 39, n. 1, p. 257-276, jan./mar. 2014. 269 
sobre o sentido da natureza, seja como expressão do mundo físico, seja como conceito que visaria a designar aquele.

Como ambos estão diretamente relacionados, o autor não só concebe como a natureza tem uma história, e não se trata da história natural, mas também como essa história foi francamente produzida pelos homens. Parte da constatação, óbvia em muitos casos ainda hoje, que muitas pessoas, ao se referirem à natureza, o fazem de maneira a não se conceberem como parte do seu emaranhado. Não é curioso que, hoje, muitos fujam das agruras do cotidiano enaltecendo as vantagens de estar próximo da natureza? Ou seja, desde aquelas práticas de lazer tidas como esportes da natureza, atividades na natureza, até aquilo que no currículo já existiu, como excursões escolares, acampamentos etc., parece que muito do que se mobilizou para formar os mais jovens adveio de um entendimento que a natureza é um outro, externo a nós, ao encontro do qual vamos quando suspendemos as nossas atividades ordinárias. "A ideia de natureza contém, embora muitas vezes de modo despercebido, uma quantidade extraordinária da história humana" (Williams, 2011, p. 89).

Percorrendo, como sempre, o desenvolvimento histórico do termo, o autor mostrará que ele surgiu como um singular que pretende uma descrição do mundo. Admitindo as dificuldades da história linguística inicial do termo, o autor, no entanto, destaca dois sentidos bastante diversos que teriam marcado a tradição ocidental. Um deles se refere a um estado na natureza. Este teria um potencial explicativo para as clivagens sociais, permitindo que o Jeca Tatu, por exemplo, como emblema de um tipo de cultura caipira, decadente, natural, representasse aquele sujeito mais próximo da natureza, longe, portanto, da culta e cultivada elite moradora das cidades brasileiras.

Mas, ao longo do seu desenvolvimento histórico, natureza se prestou tanto à definição de uma qualidade inerente de qualquer coisa, passando pela compreensão e descrição da constituição essencial do mundo físico. Isso teria constituído o cerne de uma forma idealista de compreensão, que assumiria conotação religiosa:

\begin{abstract}
A associação e, então, a fusão de um nome para a qualidade com um nome para as coisas observadas possui uma história precisa. É uma formação central do pensamento idealista. O que se buscava na natureza era um princípio essencial. A multiplicidade das coisas e dos processos da vida poderiam então ser mentalmente organizados em torno de uma única essência ou princípio: a natureza (Williams, 2011, p. 91).
\end{abstract}

Dessa maneira, o autor estabelece uma crítica contundente a um tipo de formulação que impactou o pensamento social do século XX em todo o mundo ocidental, oferecendo-nos ferramentas para compreender a dimensão profundamente ideológica de teorias de corte raciais, da eugenia, do darwinismo social e todas as formas de justificação da do- 
minação baseadas em premissas naturais, muitas delas ancoradas nas grandes obras de interpretação do Brasil (Odália, 1997; Ricupero, 2011).

Sua teoria ajuda a compreender, entre outras coisas, não só aquele lugar comum (Bresciani, 2004), próprio de diferentes intérpretes do Brasil desde Francisco Varnhagen e o IHGB, no século XIX, até modernistas como Mário de Andrade, que ajudaram a fundar a ideia de uma cultura caipira original e originária, em perfeita harmonia com a $n a-$ tureza. Permite, além disso, compreender também como se processou historicamente uma compreensão de que a formação dos indivíduos se dá pelas capacidades de aprendizagem, e essas se fundam na primazia do método, aliadas às condições inatas que cada indivíduo traz em sua bagagem biológica. No âmbito educacional, o que se viu desde o século XIX, como bem mostra Monarcha (2009) ao analisar as bases de fundamentação da chamada Escola Nova, foi o gradativo aprofundamento de retóricas que ajudariam a definir que os indivíduos são o que são em função de um mal de origem (sua natureza ou a natureza da sua classe social), e que a atuação dos educadores seria no sentido de domar ou consertar aquela natureza primeva e hostil, para que todos pudessem usufruir da marcha da civilização.

Sendo parte da crítica social vigorosa do pensamento da esquerda, as considerações de Williams para pensar a sociedade brasileira, muitas delas formuladas como contraponto às ideias evolucionistas que pontuaram o debate no âmbito das ciências sociais e da crítica cultural, revestem-se de um sentido de atualidade impressionante em tempos nos quais o pensamento crítico parece capitular. Ou seja, mais do que inovar na reflexão crítica, (re)inventando o novo, recuperar formulações de grande potência analítica é, por si só, uma possibilidade de atualizar o enfrentamento intelectual contra a apologia do pensamento único.

Hoje é notório que, como uma espécie, nós crescemos com confiança em nosso desejo e em nossa capacidade de intervir. Mas não podemos entender esse processo, não podemos nem mesmo descrevê-lo, até que estejamos cientes do que a ideia de natureza inclui e, em particular, se ela inclui o homem. Pois falar do homem "intervindo" no processo natural implica na suposição de que ele possa crer não ser possível fazê-lo, ou possa decidir não fazê-lo. A natureza tem que ser pensada, então, como separada do homem antes de qualquer questão sobre intervenção ou comando, para que o método e a ética de cada um possam surgir (Williams, 2011, p. 100).

Na sequência, remata:

É isso que vemos acontecer no desenvolvimento da ideia. Isso pode, à primeira vista, parecer paradoxal, mas o que podemos chamar de ideias mais seculares e mais racionais sobre a natureza dependeram de uma nova abstração bastante especifica: a abstração do Homem (2011, p. 101).

Educação \& Realidade, Porto Alegre, v. 39, n. 1, p. 257-276, jan./mar. 2014.

Disponível em: <http://www.ufrgs.br/edu_realidade> 
Pensando a História da Educação com Raymond Williams

Se toda uma tradição de pensamento social abstrai o homem, é forçoso reconhecer que se ara um campo fértil para toda sorte de exclusão, uma vez que nossa natureza como sociedade nos teria impingido limites e mazelas que estão além da nossa ação política deliberada. A força dos argumentos de Williams torna-se ainda maior quando observamos que a sua crítica se dirigiu também à crítica cultural, mas primeiramente ao próprio pensamento político moderno, que se fundaria nessa abstração binária natureza-homem, como uma das formas de justificação da ação política no espaço público. Essa ênfase está presente não só em A riqueza das nações, por exemplo, mas mesmo na reflexão dos contratualistas, dos utilitaristas e de algumas expressões do materialismo dialético. Por isso aqui se parte do pressuposto de que suas contribuições originais, até porque nasceram em um tempo no qual as retóricas sobre a natureza ocupavam boa parte do pensamento social, são extremamente úteis para pensarmos sobre problemas atuais da sociedade brasileira, alguns dos quais têm grande longevidade na história da nossa formação social e parecem naturalizadas nas nossas formas de compreender os dilemas brasileiros. Entre estes a educação, não apenas a escolar, mas todas as formas de educação social, as relações entre o trabalho e a vida dos trabalhadores, nossa forma de produção e distribuição de bens culturais, continuam a desafiar a capacidade de crítica da nossa sociedade.

Se Williams não produziu mirando a sociedade e a cultura brasileiras, não é casual que a recente e crescente publicação dos seus livros entre nós se dê no momento que se torna mais complexa esta cultura, ao mesmo tempo em que ela se insere em fluxos globais. Logo, em um tempo que volta a se perguntar se é possível falar de uma cultura brasileira, no qual se reivindica a inclusão digital, mas que, diferentemente do contexto inglês dos anos 1950 e 1960 por ele analisado, está longe de ver universalizado o acesso à educação escolar básica. Atento à mudança cultural, crítico de todas as formas de seleção e exclusão culturais, o pensamento de Raymond Williams é urgente como ferramenta analítica do que pretendemos para o Brasil. Para os historiadores da educação, apresenta-se como um verdadeiro índice de possibilidades de inquirição crítica do nosso passado, até porque o autor sempre aliou rigor conceitual com amplos universos empíricos na busca de elucidar como se organiza a cultura em sociedades de forte exclusão. Não seria o caso de perguntarmos pela longa tradição seletiva que continua a alijar praticamente metade dos nossos jovens de um direito tão básico como a escola pública, independentemente do juízo que possamos fazer dela? Ou seja, mais do que a história em migalhas que parece estar pontificando no campo da História da Educação, as perspectivas de Raymond Williams podem contribuir para uma história social da educação que não olvide as relações entre o micro e o macro, pautadas sempre pelo conflito, em que as classes, mas também noções como gênero, etnia, geração etc., mostrariam como a história se faz por homens e mulheres em relação, na medida em que enfrentam, atualizam e superam as condições de 
dominação, sem que isso signifique a reiteração de uma historiografia assentada em lógicas binárias conspiratórias.

\section{Concluindo}

Em Cultura e Sociedade (1978), Williams conclui que “[...] a história da ideia de cultura é a história do modo por que reagimos em pensamento e em sentimento à mudança de condições por que passou nossa vida” (p. 305). Sua reflexão o levou a uma análise arguta da chamada cultura de massas, que seu tempo viu nascer e que hoje pontua o debate sobre produção e consumo culturais. Sempre insistiu na questão de que não há massas, “[...] há apenas maneiras de ver os outros, como massa” (p. 309), discutiu o impacto das mudanças tecnológicas e as acusações de "declínio de padrões culturais", alertando para o fato de que “[...] ninguém está em condições de elevar o padrão cultural dos outros” (p. 327). Rejeita a segmentação entre, por exemplo, cultura burguesa e cultura $d a$ classe trabalhadora, já que não haveria descontinuidade entre elas, mas, sim, circularidade. Todos esses aspectos indicam a potencialidade da sua obra para pensar a educação, a cultura e suas várias histórias possíveis. Para ele, a comunicação, tão cara aos intelectuais, é o processo de transformação da experiência única em experiência comum - e todos os nossos sistemas de comunicação, incluídas as artes e a imprensa, são partes de nossa organização social (Williams, 2003).

Ainda que devamos estar atentos aos riscos do transplante conceitual, não é demais reconhecer que noções como experiência, cultura, cultura comum, estrutura de sentimentos e tradição seletiva ajudam a investigar múltiplas dimensões das formas de educação na história, seja no plano curricular, seja no das ideias, dos discursos, das prescrições etc. No plano da educação social, ajudam a compreender trajetórias, formas de pensamento, produção/recepção, circulação cultural, redes, maneiras de inserção e interação social etc.

A contribuição original de Raymond Williams, por certo um dos intelectuais mais profícuos do pensamento crítico do século XX, o é também para o pensamento marxista. Seu espírito inquiridor, não obstante, não impediu que questionasse, também, determinadas formulações daquela tradição de pensamento. Ao responder à pergunta "Você é marxista, não é?" (Williams, 1997), o autor não se furtou a apontar naquela tradição os seus limites, as suas lacunas e o que ainda era preciso desenvolver nos marcos do próprio pensamento crítico. Nem por isso deixou de inscrever sua própria obra no amplo raio de influência do pensamento marxista, pensamento que, ainda hoje, sua produção intelectual ajuda a revigorar, como crítica radical da cultura e da sociedade. Não poderia ser mais fecundo para os pesquisadores que se ocupam dos diferentes processos de formação ao longo da história.

Recebido em 27 de junho de 2012 Aprovado em 21 de junho de 2013

Educação \& Realidade, Porto Alegre, v. 39, n. 1, p. 257-276, jan./mar. 2014.

Disponível em: <http://www.ufrgs.br/edu_realidade> 


\section{Notas}

1 Este trabalho é parte dos resultados do projeto A Educação dos Sentidos na História: o tempo livre como possibilidade de formação (entre os anos finais do séc. XIX e os anos iniciais do séc. XXI), desenvolvido junto ao Núcleo de Pesquisas sobre a Educação dos Sentidos e das Sensibilidades (Nupes), da Universidade Federal de Minas Gerais/Brasil, com financiamento do CNPq sob n. 470687/2011-8, da Capes, sob n. AUX-PE-PNPD 2587/2011 e da Fapemig, sob n. APQ 00635/11. Muito do que aqui é explorado adveio de diálogos constantes com Suzete de Paula Bornato, a quem sou grato pela interlocução.

2 No âmbito da chamada nova esquerda inglesa, uma das expressões do marxismo ocidental, buscava-se uma alternativa ao socialismo real autoritário da URSS. Podemos incluir nessa tradição, também, a chamada Escola de Frankfurt (Walter Benjamin, Theodor Adorno, Max Horkheimer, Herbert Marcuse, Erich Fromm), além de destacados intelectuais franceses como Jean Paul Sartre, Maurice Merleau-Ponty, Roland Barthes, entre outros. Essa tradição intelectual marcou de forma decidida o pensamento ocidental no século XX.

3 Em texto recente, Mirian Warde (2011), ao indagar sobre as formas de tratar a disciplina História da Educação pelo campo educacional, recupera um conjunto de reflexões sobre o "sentido da história" expressas por alguns historiadores da educação brasileiros nas últimas décadas. Hobsbawm (1998), entre outros historiadores, se colocará a mesma reflexão de modo crítico e incisivo. Williams, que não era um historiador, nunca abandonou a história nas suas análises sobre a cultura.

4 A edição brasileira acrescentou mais 13 noções desenvolvidas por especialistas brasileiros, a partir do que se entende por mudanças culturais nas décadas de 1990 e 2000. Parece haver um exagero nessa decisão, uma vez que não é fácil supor que Williams estaria de acordo com as novas escolhas. Por exemplo, marxismo, arte como mercadoria, indústria cultural, parecem fora do quadro geral pensado por Williams.

5 Um dos grandes formuladores da Teoria dos Atos Linguísticos, Quentin Skinner criticará a obra de Williams por, segundo o autor, não explicitar claramente a sua compreensão que o léxico não se confunde com o conceito, apontando que "[...] existe, no entanto, uma relação sistemática entre palavras e conceitos ainda por explorar" (Skinner, 2005, p. 223).

6 Ainda que o marxismo tenha se desdobrado em inúmeras vertentes a partir do último quartil do século XIX, entre elas o chamado marxismo ocidental, Williams reconhece que a tópica marxiana fundou uma tradição vigorosa de pensamento, a despeito das suas variantes intelectuais. Pelo reconhecimento do vigor desta tradição, bem como das suas idiossincrasias, ele responderá à maneira de problematização à pergunta Você é marxista, não é?, afirmando ora aproximar-se, ora afastar-se daquela tradição de acordo com as maneiras como ela foi mobilizada. Assim, não se pode falar de várias tradições do materialismo histórico e dialético, mas de várias expressões de uma tradição de pensamento, sendo que algumas delas afetaram tanto o campo dos Estudos Curriculares, quanto o campo da História da Educação, no Brasil (Lopes; Macedo, 2002; Warde, 2011).

7 Definitivamente, Williams não se enquadra naquilo que se conhece como a história dos conceitos, campo de exploração relativamente recente entre nós, a partir da contribuição de Reinhard Koselleck (2006). Mas é possível afirmar que 
a sua busca pela mudança dos sentidos da cultura ao longo do tempo o levou a partir do pressuposto de que a linguagem é, para isso, fundamental. Como ele não parte de uma compreensão estática da língua, mas a toma como algo vivo e dinâmico, aparentemente bastante impactado pela obra de Mikhail Bakhtin, em praticamente toda a sua produção recorre a reflexões sobre a história das palavras, dos conceitos, e dos sentidos por eles expressos.

8 Em texto publicado em 2006, Alice Casimiro Lopes toma Raymond Williams para discutir a noção de cultura comum na definição do currículo nacional. Parece-me que neste exemplo há uma apropriação equivocada da formulação do autor. A cultura comum diz respeito a uma cultura comunitária compartilhada. Ou seja, o ponto de partida é o sentimento de pertencimento, a alteridade e o dialogismo. Logo, a autora se equivoca ao tratar cultura comum como cultura de massa ou cultura geral. Sobre os riscos da distorção do sentido de cultura comum nos alerta, inclusive, Michael Apple, ao negar que Williams estivesse se referindo "[...] a algo uniforme, algo a que todos nós nos conformemos" (2006, p. 27).

\section{Referências}

APPLE, Michael. Educação e Poder. Porto Alegre: Artes Médicas, 1989. APPLE, Michael. Ideologia e Currículo. Porto Alegre: Artmed, 2006. BRESCIANI, Stella. Identidades Inconclusas no Brasil do Século XX: fundamentos de um lugar-comum. In: BRESCIANI, Stella; NAXARA, Márcia (Org.). Memória e (re)sentimento: indagações sobe uma questão sensível. Campinas: Editora Unicamp, 2004. P. 399-425.

CORBIN, Alain. História dos Tempos Livres. Lisboa: Teorema, 2001.

FORQUIN. Jean-Claude. Escola e Cultura. Porto Alegre: Artes Médicas, 1993.

GOODSON, Ivor. Currículo: teoria e história. Petrópolis: Vozes, 1995.

HOBSBAWM, Eric. Sobre História. São Paulo: Companhia das Letras, 1998.

KOSELLECK, Reinhard. Futuro Passado: contribuição à semântica dos tempos históricos. Rio de Janeiro: Contraponto; Puc-Rio, 2006.

LOPES, Alice Casimiro; MACEDO, Elizabeth. O Pensamento Curricular no Brasil. In: LOPES, Alice Casimiro; MACEDO, Elizabeth (Org.). Currículo: debates contemporâneos. São Paulo: Cortez Editora, 2002. P. 13-54.

LOPES, Alice Casimiro. Quem Defende os PCNs para o Ensino Médio? In: LOPES, Alice Casimiro; MACEDO, Elisabeth (Org.). Políticas de Currículos em Múltiplos Contextos. São Paulo: Cortez, 2006. P. 126-158.

MONARCHA, Carlos. Brasil Arcaico, Escola Nova. São Paulo: Editora UNESP, 2009.

ODÁLIA, Nilo. As Formas do Mesmo. São Paulo: Editora UNESP, 1997.

OSCAR, Luisa Belotti; TABORDA DE OLIVEIRA, Marcus Aurelio. Periódicos e Imprensa como Fontes para a História da Educação dos Sentidos em Minas Gerais: o tempo livre como possibilidade de formação (entre as décadas finais do séc. XIX e as décadas iniciais do séc. XX). In: CONGRESSO BRASILEIRO DE HISTÓRIA DA EDUCAÇÃO, 7., 2013, Cuiabá. Anais... Cuiabá: SBHE, 2013.

PINKNEY, Tony. Modernismo e Teoria da Cultura: prefácio à edição inglesa. In: WILLIAMS, Raymond. Política do Modernismo. São Paulo: UNESP, 2011. P. XIXLX.

Educação \& Realidade, Porto Alegre, v. 39, n. 1, p. 257-276, jan./mar. 2014. 
RICUPERO, Bernardo. Sete Lições sobre as Interpretações do Brasil. São Paulo: Alameda, 2011.

SARLO, Beatriz. Paisagens Imaginárias. São Paulo: EDUSP, 2005.

SKINNER, Quentin. Visões da Política. Sobre os métodos históricos. Lisboa: Difel, 2005

TABORDA DE OLIVEIRA, Marcus Aurélio. O Lugar do Intelectual: a experiência do intelectual Rocha Pombo no processo de constituição de uma longa tradição seletiva. In: HANDAN, Juliana et al. (Org.). Moderno, Modernidade e Modernização: a educação nos projetos de Brasil (séculos XIX e XX). Belo Horizonte: Mazza Editora, 2013 (no prelo).

WARDE, Mirian Jorge. Pesquisa e Ensino em História da Educação. In: GONDRA, José; SILVA, José Cláudio Sooma (Org.). História da Educação na América Latina: ensinar e escrever. Rio de Janeiro: EDUERJ, 2011. P. 243-264.

WILLIAMS, Raymond. Cultura e Sociedade. São Paulo: Companhia Editora Nacional, 1978.

WILLIAMS, Raymond. Marxismo e Literatura. Rio de Janeiro: Zahar, 1979.

WILLIAMS, Raymond. O Campo e a Cidade. São Paulo: Companhia das Letras, 1989.

WILLIAMS, Raymond. Cultura. Rio de Janeiro: Zahar, 1991.

WILLIAMS, Raymond. Você é Marxista, Não é? Praga: Revista de Estudos Marxistas, São Paulo, Boitempo, n. 2, p. 123-133, 1997.

WILLIAMS, Raymond. La Larga Revolución. Buenos Aires: Nueva Vision, 2003.

WILLIAMS, Raymond. Tragédia Moderna. São Paulo: Cosac Naify, 2005.

WILLIAMS, Raymond. Palavras-Chave: um vocabulário de cultura e sociedade. São Paulo: Boitempo Editorial, 2007.

WILLIAMS, Raymond. A Política do Modernismo. São Paulo: Editora UNESP, 2010.

WILLIAMS, Raymond. Cultura e Materialismo. São Paulo: Editora UNESP, 2011.

Marcus Aurelio Taborda de Oliveira é professor da Universidade Federal de Minas Gerais, onde coordena o Núcleo de Pesquisa sobre a Educação dos Sentidos e das Sensibilidades (Nupes), vinculado ao Centro de Estudos e Pesquisa em História da Educação (GEPHE). Doutor em História e Filosofia da Educação pela PUC/SP, com pós-doutoramento na Universidad de Murcia, Espanha. É bolsista em produtividade do CNPq e do Programa Pesquisador Mineiro, da Fapemig.

E-mail: marcustaborda@pq.cnpq.br 